\title{
BMJ Open Prenatal Exposure And Child brain and mental Health (PEACH) study: protocol for a cohort study of children and youth with prenatal alcohol exposure
}

\author{
Catherine A Lebel (1) , ,2,3 W. Ben Gibbard, ${ }^{2,4}$ Christina Tortorelli, ${ }^{5}$ Jacqueline Pei, ${ }^{6}$ \\ Christian Beaulieu, ${ }^{7}$ Mercedes Bagshawe, ${ }^{1,2,3}$ Carly A McMorris ${ }^{2,8}$
}

To cite: Lebel CA, Gibbard WB, Tortorelli C, et al. Prenatal Exposure And Child brain and mental Health (PEACH) study: protocol for a cohort study of children and youth with prenatal alcohol exposure. BMJ Open 2021;11:e051660. doi:10.1136/ bmjopen-2021-051660

- Prepublication history for this paper is available online. To view these files, please visit the journal online (http://dx.doi org/10.1136/bmjopen-2021 051660).

Received 24 March 2021 Revised 14 April 2021 Accepted 16 April 2021

Check for updates

(C) Author(s) (or their employer(s)) 2021. Re-use permitted under CC BY-NC. No commercial re-use. See rights and permissions. Published by BMJ.

For numbered affiliations see end of article.

Correspondence to Dr Catherine A Lebel; clebel@ucalgary.ca

\section{ABSTRACT}

Introduction Fetal alcohol spectrum disorder (FASD), which is caused by prenatal alcohol exposure (PAE), affects an estimated $4 \%$ of North Americans, and is the most common preventable cause of intellectual disability. Mental health problems, including anxiety and depression, are experienced by nearly all individuals with FASD. However, there is very limited knowledge about effective mental health treatments for individuals with FASD; effective treatments are hindered in part due to a lack of understanding of the basic neurobiology underlying internalising disorders in youth with FASD.

Methods and analysis The Prenatal Exposure And Child brain and mental Health (PEACH) study includes children aged 7-18 years. We will use longitudinal neuroimaging (anatomical T1-weighted, diffusion and passive viewing function MRI) and mental health assessments (Behaviour Assessment Scale for Children, Multi-dimensional Anxiety Scale for Children, Children's Depression Inventory (CDI2), Kiddie Scale of Affective Disorders) to: (1) characterise brain development trajectories in youth with FASD, (2) determine whether brain alterations mediate increased anxiety and depression in youth with FASD and (3) identify baseline brain features that predict changes of anxiety and depression symptoms over the next 2 years. All of this will be done while considering sex and adverse postnatal experiences, which can significantly impact mental health and brain outcomes. This project will forge new understanding of FASD and mental health from a neurobiological perspective, highlighting key time periods (ie, sensitive windows) and brain regions (ie, that may be susceptible to neurostimulation), while identifying factors that predict individual trajectories of anxiety and depression symptoms.

Ethics and dissemination This study was approved by the University of Calgary Conjoint Health Research Ethics Board and the University of Alberta Health Research Ethics Board. Study results will be disseminated in peer-reviewed journals, at relevant conferences and in conjunction with our knowledge mobilisation partners.

\section{INTRODUCTION}

Fetal alcohol spectrum disorder (FASD) is a neurodevelopmental disorder caused by prenatal alcohol exposure (PAE). It
Strengths and limitations of this study

- We use longitudinal neuroimaging to assess brain structure and brain growth.

- Alcohol-exposed participants will have confirmed prenatal alcohol exposure, though specific measures of timing, frequency and dose of prenatal alcohol exposure may be difficult to obtain.

- We use multiple mental health assessments to measure symptoms of depression and anxiety, and include a comprehensive neurocognitive battery.

- This study uses a longitudinal, prospective design and will follow children over 2 years.

- We incorporate comprehensive assessment and analysis of both prenatal and postnatal adverse exposures.

is characterised by life-long cognitive, behavioural and neurological deficits. ${ }^{1}$ The prevalence of FASD in North America is estimated to be $4 \%,{ }^{2}{ }^{3}$ with lifetime costs over \$C 1 million per individual. ${ }^{3-5}$ Beyond the primary cognitive and behavioural deficits, over $90 \%$ of individuals with FASD experience co-occurring mental health problems, ${ }^{6-8}$ compared with $20 \%$ in the general population. ${ }^{9}$ Depression and anxiety are among the most common, affecting $45 \%-50 \%$ and $20 \%-40 \%$ of individuals with FASD, respectively. ${ }^{10-12}$ Developing early and appropriate interventions to minimise mental health problems and maximise adaptive outcomes in FASD is critical for improving quality of life and reducing the societal burden of FASD. Concerns have been raised that existing mental health treatments for individuals with FASD may be less effective than for the general population, ${ }^{13} 14$ perhaps hindered by a lack of understanding of their neurobiological basis.

MRI can be used to investigate neurological abnormalities in FASD. The most common 
MRI finding in individuals with FASD is widespread reductions in brain volume, which have been observed with anatomical MRI from neonates to adults. ${ }^{15-17}$ Diffusion tensor imaging assesses microstructure of structural white matter connections via fractional anisotropy (FA) and mean diffusivity (MD), measures sensitive to myelination and axonal density. ${ }^{18}$ Numerous studies have shown lower FA and/or higher MD in children, adolescents and young adults with FASD ${ }^{19-22}$ Recent studies suggest that brain diffusion alterations are also present in infants and young children, though in the opposite direction (ie, higher FA and lower diffusivity). ${ }^{24}$ Resting state functional MRI (rs-fMRI) measures patterns of spontaneous brain connectivity by correlating functional signals across regions ('functional connectivity') ${ }^{25}$; findings suggest atypical functional connectivity in children and youth with FASD. ${ }^{26-29}$ Regional brain volume reductions, weaker white matter connectivity (lower FA/higher MD, and atypical functional connectivity have been reported throughout the brain, but alterations are most prominent in subcortical structures ${ }^{1730}$ and prefrontal areas. ${ }^{20} 29-31$ Most studies to date have been cross-sectional, and thus the trajectories of brain maturation remain unclear. The few longitudinal MRI studies that do exist in FASD show that children with FASD have faster changes of cortical thickness, ${ }^{32}$ volume $^{33}$ and white matter connectivity ${ }^{34}$ than unexposed controls; these faster changes possibly reflect a 'catch-up' in brain maturation. It is not known how key functional networks change with age in FASD. Longitudinal research is critical for revealing the developmental trajectories of brain connectivity in FASD.

Previous studies have related cognitive abilities and clinical features (eg, dysmorphology) to brain structure in FASD ${ }^{29}{ }^{33} 35-38$; however few studies have examined relationships between brain measures and mental health. ${ }^{39}$ In individuals without FASD, internalising symptoms are most commonly associated with brain alterations in the anterior cingulate cortex (ACC), medial prefrontal cortex (mPFC), dorsolateral prefrontal cortex (dlPFC), amygdala and hippocampus, as well as connections between these structures. ${ }^{40-42}$ Resting state functional connectivity is higher in the ACC and MPFC in adolescents with depression, ${ }^{42}{ }^{43}$ while weaker structural connectivity (lower FA and/or higher MD) in frontal white matter (eg, cingulum, uncinate) is associated with depression and anxiety in youth. ${ }^{44-49}$ Areas identified by neuroimaging (eg, prefrontal cortex, cingulate) can be used as brain targets for neurostimulation to treat adults with depression and anxiety, ${ }^{50-52}$ highlighting the importance of understanding the neurological correlates of internalising symptoms. Given the overlap between structures identified as atypical in children and youth with FASD, and brain areas associated with anxiety and depression, brain alterations induced by PAE may underlie, at least in part, the increased the risk of internalising disorders.

Little is known about the trajectories of mental health symptoms in youth with FASD, though difficulties tend to persist or worsen with age. ${ }^{53}{ }^{54}$ However, FASD is a heterogenous disorder, with heterogeneous outcomes, ${ }^{55}$ so it is critical to consider differences at the individual level. In adolescents without FASD, functional connectivity between the amygdala and mPFC predicts the severity of future internalising symptoms ${ }^{56}$ Brain volumes in the hippocampus ${ }^{57}$ and ACC $^{58}$ also predict treatment response in adults with depression (but without FASD). However, it is unclear which baseline features predict future mental health outcomes in youth with FASD, though this could inform treatment decisions. Thus, longitudinal research is needed to understand associations between brain alterations and trajectories of depressive and anxiety symptoms in individuals with FASD, to help predict individual outcomes.

Individuals with PAE/FASD frequently have adverse postnatal experiences ( 43\% have abuse or neglect) ${ }^{59-61}$ Such early adversity is commonly operationalised as adverse childhood experiences (ACEs), ${ }^{62}$ which provides a cumulative risk score accounting for abuse, neglect and other household dysfunction in childhood. In the general population, ACEs are associated with heightened risk of anxiety and depression ${ }^{63}$ and alterations to frontal and limbic brain structure and function. ${ }^{64-72}$ Animal studies show that PAE and postnatal adversity interact to increase depression risk. ${ }^{73}$ However, few human studies of FASD have incorporated any measure of postnatal risk. Two recent human studies show differential associations between socio-economic status and brain volumes in children with and without PAE, ${ }^{74} 75$ and one showed that postnatal adversity (neglect, abuse, etc) moderates the association between PAE and brain connectivity. ${ }^{22}$ All of this evidence underscores the need for FASD studies to consider postnatal adversity. ACEs treats all adverse experiences similarly, although different types of adversity may have different effects on individuals. ${ }^{76}$ We recently developed a risk characterisation framework that accounts for the duration, frequency, timing and type of risks, which we believe is more appropriate for children with PAE who may experience a wide range of adversities. ${ }^{60}$

Understanding brain development in individuals with FASD, its relation to internalising symptoms and predictors of positive outcomes is critical for targeting treatments at the right time (eg, age-appropriate therapy) ${ }^{77}$ for the right brain regions (eg, for neurostimulation) ${ }^{50}$ and for the right person (eg, considering individual circumstances) ${ }^{78}$ In this study, we will recruit 125 youth with heavy PAE or FASD and 125 control youth (7-18 years) and acquire longitudinal MRI and mental health assessments to study trajectories of brain and mental health with the following aims:

1. Characterise developmental trajectories of brain connectivity in youth with FASD. Hypothesis 1: Structural and functional connectivity to the prefrontal cortex, hippocampus and amygdala will show faster increases in FASD compared with unexposed controls.

2. Determine whether brain structure and function mediate the relationship between FASD and internalising symptoms. Hypothesis 2: Brain connectivity between the 
amygdala, hippocampus and prefrontal cortex (specifically, lower FA, higher MD, and stronger functional connectivity) will mediate the association between FASD and symptoms of anxiety and depression.

3. Identify baseline factors that predict changes of internalising symptoms over time in youth with FASD. Hypothesis 3: Weaker structural connectivity, stronger functional connectivity and smaller brain volumes at baseline will predict worsening anxiety and depressive symptoms over the subsequent 2 years.

\section{METHODS AND ANALYSIS \\ Participants}

We will recruit 125 children and youth with heavy PAE or FASD and 125 unexposed controls aged 7-18 years. This age range was chosen because: (1) FASD diagnosis typically occurs at or after age $\sim 6-7$ years in Alberta, ${ }^{79}$ (2) 7-18 years includes the most common ages of onset for anxiety disorders, ${ }^{80}$ (3) depression and anxiety symptoms are common in youth with PAE of this age range ${ }^{8}$ and (4) children this age are more likely to tolerate MRI scanning than younger children. ${ }^{81}$ Repeat assessments and MRI scanning will occur 2 years after baseline, which allows for measurable brain development within individuals, ${ }^{82}$ as well as meaningful changes in mental health symptoms. Approximately equal numbers of men and women will be recruited to be able to appropriately examine sex effects, and approximately half in Edmonton and half in Calgary. Informed written consent will be obtained from parents/ guardians, as well as written assent from children/youth.

\section{FASD/PAE group}

Participants will be recruited through diagnostic clinics throughout Alberta (including the Pediatric FASD Clinic at the Glenrose Hospital in Edmonton and the Cumulative Risk Diagnostic Clinic at the Alberta Children's Hospital in Calgary), Alberta Children's Services, parent/ caregiver support groups for FASD, community groups (eg, Calgary and Edmonton Fetal Alcohol Networks), as well as online advertisements and word of mouth.

Participants in the PAE group must have a diagnosis of FASD or confirmed heavy PAE at levels consistent with Canadian FASD diagnostic guidelines ( $\geq 7$ drinks/week or $\geq 2$ binge episodes at some point during pregnancy). ${ }^{1}$ Alcohol exposure will be confirmed via biological mother's self-report, reliable observations by close family or friends, clinical observation, and/or medical, legal or child services records. Additional prenatal exposures (eg, tobacco, cannabis, illicit drugs) and adverse experiences (eg, lack of prenatal care, maternal mental health problems) will be documented where information is available. ${ }^{60}$ Participants with genetic disorders associated with significant intellectual or developmental impairments, diagnosed with a neurological disorder (eg, epilepsy, cerebral palsy), or with contraindications to MRI (ie, metal implants, dental devices, claustrophobia) will be excluded. Participants will not be excluded for common comorbid developmental disorders such as attention deficit hyperactivity disorder (ADHD) or learning disabilities.

\section{Control group}

Controls must have confirmed absence or minimal PAE ( $\leq 5$ drinks total in pregnancy, with no binge episodes) via biological maternal report, no diagnosis of genetic or neurological disorders and no contraindications to MRI scanning. Controls will be recruited through online advertisements, parent groups in Edmonton and Calgary and word of mouth. Controls must not have significant intellectual or developmental impairments, but will not be excluded for neurodevelopmental disorders such as ADHD or learning disabilities.

\section{MRI scanning}

MRI scanning at baseline and 2-year follow-up will take place at the Alberta Children's Hospital (Calgary) on a research-dedicated General Electric 3T MR750w system, or at the Peter S Allen MRI Centre (Edmonton) on a research-dedicated Siemens 3T Prisma. The imaging protocol is detailed in table 1 .

\section{Image analysis}

T1-weighted images will be processed using FreeSurfer's $^{83}$ longitudinal processing stream. ${ }^{84}$ Each subject's parcellation will be manually checked and receive minor corrections if necessary. Brain volumes of the left and right hippocampus, amygdala and prefrontal cortical areas (dACC, dlPFC, mPFC) will be extracted.

Diffusion data will be quality checked, brain extracted and corrected for eddy currents and head motion. FA and MD maps will be generated for each subject. Tractography (FA $>0.2$, angle $<30^{\circ}$ ) will be used to reconstruct white matter fibres connecting frontal and limbic regions (uncinate fasciculus, cingulum, fornix). FA and MD will be assessed within each white matter fibre bundle as primary variables of interest. The dual b-value scan also allows for more advanced diffusion models and analysis,${ }^{85} 86$ which will be examined in follow-up analyses after primary aims are complete.

Assessment of rs-fMRI data will use AFNI and FSL tools. ${ }^{8788}$ Each individual's fMRI data will be registered to their anatomical (T1-weighted) scan, then to a paediatric brain template for $5-18$ year olds. ${ }^{88}{ }^{89}$ Volumes with high framewise displacement $(>0.25 \mathrm{~mm})$ will be identified and regressed out. Scans with $<5$ min of low-motion data will be eliminated. For each prefrontal region (dlPFC, mPFC, dACC) and the hippocampus and amygdala, averaged time courses will be generated. Correlations between time courses in each pair of regions will be analysed to measure functional connectivity.

\section{Mental health assessments}

Mental health assessments will occur at baseline, a subset of tests will be administered online at 1-year follow-up, and the full set will be administered again at 2-year follow-up (see table 2). Symptoms of depression and anxiety will 
Table $1 \mathrm{MRI}$ protocol. Parameters are given for GE MR750w before Siemens Prisma; if only one set of parameters is given, they were the same for both scanners

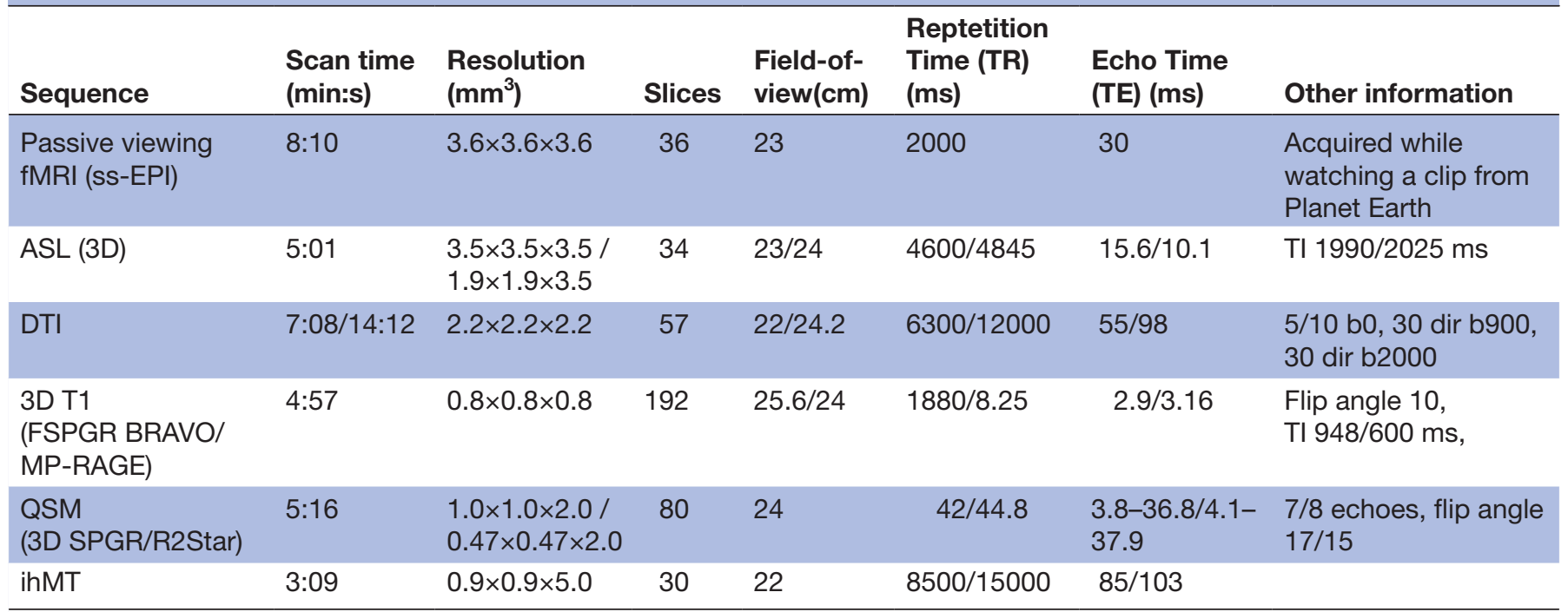

ASL, arterial spin labelling; DTI, diffusion tensor imaging; EPI, echo planar imaging; fMRI, functional MRI; FSPGR, fast spoiled gradient; inMT, inhomogeneous magnetisation transfer; MP-RAGE, magnetisation prepared rapid acquisition gradient echo; QSM, quantitative susceptibility mapping; SPGR, spoiled gradient; ss-EPI, single shot echo planar imaging.

be measured using both self-reports and caregiver-reports on the Behaviour Assessment System for Children (BASC$3){ }^{90}$ Child Depression Inventory-2 (CDI-2) $)^{91} 92$ and the Multidimensional Anxiety Scale for Children (MASC-2) ${ }^{93}$ The MASC-2 is a self-report assessment of anxiety symptoms in children and adolescents (8-19 years of age); MASC-2 will not be used for the youngest children aged 7 years. The CDI-2 is a brief questionnaire that measures cognitive, affective and behavioural signs of depression in children and adolescent ages $7-17$ years. We will use the Beck Depression Inventory ${ }^{94}$ to assess depression symptoms in youth/young adults $\geq 18$ years, and the PROMIS Anxiety Short Form ${ }^{95}$ to assess anxiety symptoms in young adults aged 20 years. The BASC- 3 provides a validated assessment of a range of mental health symptoms, including anxiety and depression, while the CDI-2 and MASC-2 provide more specific measures of depression and anxiety symptoms, respectively, that are consistent with diagnostic criteria. The BASC-3 caregiver report and self-report (only children $\geq 12$ ) will be used to assess behaviour.

To determine whether an individual meets diagnostic criteria for anxiety or depression, youth $\geq 12$ years of age and all caregivers will complete a diagnostic assessment of internalising mental health disorders with a trained and reliable clinician using the mood and affective disorders subscales of Kiddie Schedule for Affective Disorders and Schizophrenia - Lifetime Version (K-SADS-PL) ${ }^{96}$ The K-SADS-PL is a semi-structured diagnostic interview and gold standard for assessing a variety of mental health disorders in youth based on Diagnostic and Statistical Manual of Mental Disorders (DSM-5) diagnostic criteria. ${ }^{97}$ The Diagnostic Interview for Anxiety and Mood, and OCD and Related Neuropsychiatric Disorders (DIAMOND) ${ }^{98}$ will be used for participants over 18 years.

We also examine the frequency, chronicity and location of pain of children and youth in the past 30 days. ${ }^{99} 100$ The Adaptive Behaviour Assessment System is a comprehensive parent report measure of the adaptive or daily functioning skills of children and youth across the lifespan. ${ }^{101}$ The Sensory Profile measures a child's sensory processing patterns in various contexts (home, school and community settings). ${ }^{102}$

\section{Cognitive assessments}

IQwill be assessed using the Wechsler Abbreviated Scale of Intelligence - Second Edition ${ }^{103}$ 2-subtest form at baseline to obtain an estimate of Full Scale IQ. The Rey-Osterrieth Complex Figure Test ${ }^{104}$ examines visuospatial ability and visuospatial memory in individuals between 6-89 years of age. The Wisconsin Card Sorting Test ${ }^{105}$ is an executive functioning measure used to determine cognitive flexibility and set shifting in individuals 6.5-89 years of age. The California Verbal Learning Test (CVLT-C) measures learning and long-term recall and recognition of verbal information in 5-16.11 year olds. ${ }^{106}$ The CVLT-3 will be used for youth $\geq 17$ years. The NEPSY-II is a neuropsychological assessment tool for children aged 3-16 years of age that assesses functioning in six domains ${ }^{107}$; we will use the subscales of inhibition (measuring inhibition) and word generation (verbal productivity). The Wechsler Individual Achievement Test measures academic abilities in children and adolescents aged $4-50.11$ years. ${ }^{108}$

\section{Early adversity}

Adverse postnatal exposures are assessed using questions adapted from the National Crittenton Foundation 
Table 2 Questionnaires and assessments

\section{Time 1 (in person) Time 2 (online) Time 3 (in person) Age limits}

\begin{tabular}{|c|c|c|c|c|}
\hline \multicolumn{5}{|l|}{ Mental health } \\
\hline Child Depression Index & $\begin{array}{l}\text { Caregiver report } \\
\text { Self-report }\end{array}$ & $\begin{array}{l}\text { Caregiver report } \\
\text { Self-report }\end{array}$ & $\begin{array}{l}\text { Caregiver report } \\
\text { Self-report }\end{array}$ & $\begin{array}{l}\text { Beck Depression Inventory used } \\
\text { for youth }>17 \text { years }\end{array}$ \\
\hline $\begin{array}{l}\text { Kiddie Scale of Affective } \\
\text { Disorders and Schizophrenia }\end{array}$ & $\begin{array}{l}\text { Caregiver interview } \\
\text { Child interview }\end{array}$ & & $\begin{array}{l}\text { Caregiver interview } \\
\text { Child interview }\end{array}$ & $\begin{array}{l}\text { Child interview only conducted } \\
\text { with children } \geq 12 \text { years } \\
\text { DIAMOND used for young adults } \\
>18 \text { years }\end{array}$ \\
\hline
\end{tabular}

$\begin{array}{lll}\text { Adaptive Behaviour } & \text { Caregiver report } & \text { Caregiver report } \\ \text { Assessment System } & & \end{array}$

Assessment System

Caregiver report

Pain questionnaire

Child report

\begin{tabular}{|c|c|c|c|c|}
\hline Sensory Profile & Caregiver report & & Caregiver report & Only used for children $<15$ years \\
\hline \multicolumn{5}{|l|}{ Cognitive functioning } \\
\hline $\begin{array}{l}\text { Wechsler Abbreviated Scale of } \\
\text { Intelligence } 2 \text {-subtest form }\end{array}$ & $\begin{array}{l}\text { Matrix reasoning, } \\
\text { vocabulary }\end{array}$ & & & \\
\hline $\begin{array}{l}\text { Rey-Osterrieth Complex Figure } \\
\text { Test }\end{array}$ & Child & & Child & \\
\hline $\begin{array}{l}\text { Wechsler Individual } \\
\text { Achievement Test }\end{array}$ & $\begin{array}{l}\text { Word reading, } \\
\text { pseudo-word } \\
\text { reading, oral reading } \\
\text { fluency, reading } \\
\text { comprehension, } \\
\text { numerical operations }\end{array}$ & & $\begin{array}{l}\text { Word reading, } \\
\text { pseudo-word } \\
\text { reading, oral reading } \\
\text { fluency, reading } \\
\text { comprehension, } \\
\text { numerical operations }\end{array}$ & \\
\hline NEPSY-II & $\begin{array}{l}\text { Inhibition, word } \\
\text { generation }\end{array}$ & & $\begin{array}{l}\text { Inhibition, word } \\
\text { generation }\end{array}$ & $\begin{array}{l}\text { Only conducted with children } \\
<17 \text { years }\end{array}$ \\
\hline \multicolumn{5}{|l|}{ Other information } \\
\hline Demographic questionnaire & Caregiver & Caregiver & Caregiver & \\
\hline $\begin{array}{l}\text { Prenatal and postnatal } \\
\text { exposure assessment }\end{array}$ & $\begin{array}{l}\text { Caregiver; medical, } \\
\text { legal, children's } \\
\text { services records }\end{array}$ & & & \\
\hline Puberty questionnaire & Caregiver, child & Caregiver, child & Caregiver, child & \\
\hline Gender identity questionnaire & Caregiver, child & & & \\
\hline $\begin{array}{l}\text { Adverse childhood } \\
\text { experiences }\end{array}$ & $\begin{array}{l}\text { Caregiver on behalf } \\
\text { of child }\end{array}$ & & & \\
\hline
\end{tabular}

Questionnaire and assessments are listed below for each study time point. Caregiver refers to a parent or guardian who regularly cares for the child. Study personnel support younger children in completing the questionnaires if necessary.

DIAMOND, Diagnostic Interview for Anxiety and Mood, and OCD and Related Neuropsychiatric Disorders; NEPSY-II, A Developmental NEuroPSYchological Assessment, 2nd Edition.

ACEs survey, ${ }^{62} 109$ a validated survey deemed acceptable by families and caregiving agencies. ${ }^{110}$ For children in foster or adoptive care, adverse experiences will be ascertained through child services records and interviews with biological and/or adoptive parents. With this information and information about prenatal exposures (see above), we will apply our own characterisation tool, which accounts for the timing, amount, and type of adverse exposure(s) experienced both prenatally and postnatally. $^{60}$ 


\section{Other variables}

Caregivers will complete a comprehensive demographic survey that includes information about other individuals in the house, household income, parent education and ethnicity. Caregivers will be asked if youth have other diagnoses or are taking medications. Depending on the age and abilities of the youth, they and/or their caregiver will be asked to complete a short questionnaire about puberty. Youth will be asked to self-report their sex and gender. Sex will be included as a covariate in all analyses, and sex-by-age or sex-by-anxiety/depression interaction terms will be included where appropriate. Gender and its interaction terms will be used as additional covariates if numbers permit.

\section{Statistical analysis}

Statistical analysis will occur in SPSS (IBM), R (www.rproject.org) and Matlab. Aim 1 will begin with a crosssectional analysis using a regression model including age, sex, group and age-by-group interaction terms, run separately for each brain measure. Once longitudinal data is available, linear mixed effects models in $\mathrm{R}$ (using lme4 and lmerTest) ${ }^{111} 112$ will be used to determine developmental patterns of structural and functional connectivity for the FASD and control groups. Subject will be modelled as a random factor, with sex, age, group and age-by-group included in the model. For both cross-sectional and longitudinal analyses, postnatal adversity and IQ will be included as covariates. Mixed effects models will be run separately on volumes of each region, structural connectivity (FA) for each white matter tract, and functional connectivity (correlation) for connections between each pair of regions in the prefrontal-amygdala-hippocampus network (shown in figure 1). False discovery rate will be used to correct for multiple comparisons.

For Aim 2, mediation will be carried out by testing the first pathway from the main predictor (PAE) to each brain measure (volume, structural or functional connectivity), controlling for age and sex of participants, and then testing the second pathway from each brain measure to each mental health measures (anxiety or depression symptoms), with age, sex and postnatal adversity as

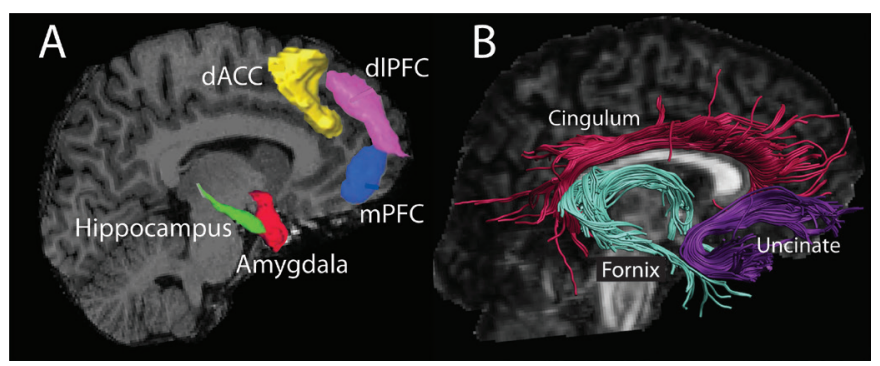

Figure 1 Key grey matter regions $(A)$ and white matter connections (B) related to anxiety and/or depression symptoms. Volume of the regions in A, functional connectivity between pairs of regions in $A$ and structural connectivity (diffusion metrics) of tracts in B will be measured. dACC, dorsal anterior cingulate cortex; dIPFC, dorsolateral prefrontal cortex; mPFC, medial prefrontal cortex. covariates. The overall mediation effect will be tested using percentile-based bootstrap CIs, computed from 5000 simulations. ${ }^{113}$ Caregiver-report $T$-scores from the CDI-2 and MASC-2 will be used as primary measures of depression and anxiety symptoms, respectively. BASC-3 $T$-scores on the anxiety and depression subscales of internalising symptoms will be used as secondary information. Self-report scores will be used for supplementary analysis, as they sometimes provide different information. ${ }^{114} 115$

For Aim 3, change in anxiety and depression symptoms will be calculated by subtracting the $T$-scores at Time 2 from the $T$-score at Time 1 . Primary variables will be caregiver-reported CDI-2 and MASC-2 scores for depression and anxiety, respectively. Brain measures, postnatal adversity, sex, IQ, age and group will then be entered into a multiple regression model to determine which baseline factors predict anxiety and depression trajectories over time. Change in BASC-3 T-scores on the anxiety and depression subscales over the 2 years, as well as self-report scores on CDI-2 and MASC-2 will be used in a supplementary analysis. Initially, change in anxiety and depression outcomes will be used as a continuous measure. If enough youth meet criteria for a diagnosis of a depression or anxiety disorder (as measured by the K-SADS), a group analysis (those whose symptoms changed in severity to meet criteria for a diagnosis vs those whose did not) will also be conducted.

\section{Power calculations}

We collected preliminary data, including MRI, mental health assessments and postnatal adversity on 17 children with FASD and 19 controls without PAE aged 7-15 years. Control subjects (part of a different study) ${ }^{85} 86$ had follow-up scans and assessments $\sim 2$ years later. This preliminary data showed age-by-group interactions in structural and functional connectivity with effect sizes of 0.067-0.192 (partial eta ${ }^{2}$ ). To detect effects this size for Aim 1 with power $\geq 0.8$ using an analysis of variance (ANOVA) with main effects and interactions, we require 112 individuals in total (calculated in $\mathrm{G}^{*}$ Power). Preliminary data shows small-medium effects for both FASD-brain and brain-anxiety pathways in the mediation. According to simulations, ${ }^{116}$ these effects require a sample size of $\geq 162$ total individuals to detect mediation using percentile bootstrap with power $\geq 0.8$ (Aim 2). Linear regression of relationships between brain measures and changes in anxiety and depression in controls showed effects of $r=0.4-0.6$. To detect these effects (Aim 3), we require at least 130 participants in total (G*Power). Thus, we aim to have $\geq 162$ individuals in total (81 per group) at time 1 (Aims 1 and 2), and $\geq 130$ (65 per group) with longitudinal data (Aims 1 and 3).

\section{Patient and public involvement}

CT (co-investigator on the project) was an Associate Director of Alberta Children's Services and was involved in study design. She has since moved on to a role as Assistant Professor at Mount Royal University and remains 
involved with the project. We continue to involve staff from Children's Services in the design and execution of the study, and will involve them in interpretation and dissemination of findings. We also have active relationships with organisations serving individuals with FASD and their families, including the Calgary and Edmonton Fetal Alcohol Networks and CanFASD (co-investigator JP is Senior Research Lead/Intervention Lead at CanFASD). These organisations have provided study feedback and support and will assist with interpretation and dissemination of findings.

\section{Potential limitations}

Research on children and youth with FASD is complex due to confounding prenatal and postnatal exposures, missing information and behavioural difficulties. If recruitment or retention are lower than anticipated, we will recruit participants outside Calgary and Edmonton (eg, through the other 10 FASD Networks across Alberta). The strict diagnostic criteria used here will ensure that all participants have a minimum level of PAE, though exact amounts may not be known. We will use all available sources to characterise other risks and diagnoses in our participants and will statistically control for these in our analyses. ${ }^{60}$ In some cases, information will be missing, which is a challenging but unavoidable aspect of doing research in this population.

\section{Significance}

FASD is a common disorder ( $4 \%$ of Canadians) with a very high societal cost $(>\$ 17 \mathrm{~B}$ annually). Most individuals with FASD experience co-occurring mental health issues throughout their lifespan, but effective treatments are hindered by a lack of understanding of the neurobiological basis for these problems. The use of quantitative MRI to understand the brain abnormalities and atypical development patterns underlying mental health problems in youth with FASD is critical to early identification and appropriate intervention strategies to improve outcomes. This study will reveal developmental patterns of brain connectivity, identify the underlying neurological correlates of anxiety and depression symptoms in youth with FASD and identify baseline brain features that can predict the worsening of anxiety and depression symptoms. This knowledge is crucial for advancing research and identifying prevention and early intervention strategies, which will have substantial benefits for children and youth with FASD, their families and the public health system and society. This innovative project will address significant gaps in the literature, inform prevention strategies and promote early detection and intervention of internalising issues in children and youth with FASD.

\section{ETHICS AND DISSEMINATION}

This study has been approved by the University of Calgary Conjoint Health Research Ethics Board (REB17-0663) and the University of Alberta Health Research Ethics
Board (Pro00093230). Data collection takes 4-6 hours for youth, and 2-3 hours for caregivers (table 1) and occurs at the Alberta Children's Hospital (Calgary) or University of Alberta Hospital (Edmonton). Caregivers complete some questionnaires ahead of the visit, and additional questionnaires and interviews during the visit. Children complete the MRI scan, mental health and neuropsychological assessments and questionnaires during the visit. Children $\geq 12$ years complete the KSADS interview. Breaks are given and support is provided as necessary for children and youth. Snacks, parking and an honorarium (\$150 at baseline visit, $\$ 50$ at 1-year visit and $\$ 250$ at 2-year visit) are provided for each family. The honorarium reflects the commitment of the families, as this study requires substantial time commitments from both the child and the caregiver. If an MRI reveals any incidental findings, it will be referred to the site's medical director (a neuroradiologist) for review and follow-up. If the mental health assessments reveal any concerns, youth will be referred by a child clinical psychologist (CAM or JP) for appropriate follow-up through the child's physician or other appropriate mental health services.

Communication of our findings to other researchers will occur via publications in peer-reviewed journals and presentations at relevant conferences (eg, Organization for Human Brain Mapping, Canadian Academy of Child \& Adolescent Psychiatry). As we publish our research findings, we will produce lay summaries and infographics for distribution to stakeholders via our website, our Twitter accounts, Kids Brain Health Network's website (researchimpact.ca), social media (including Kids Brain Health Network's YouTube, Facebook and Twitter accounts), and email.

Knowledge translation to the wider community will include direct communication (via reports, presentations, meetings) with diagnostic clinics and Children's Services. Results will be presented at policy and practice meetings (eg, International Conference on Child and Family Maltreatment, Canadian Association of Pediatric Health Centres, Canadian Pediatric Society, Alberta College of Social Workers).

\section{Author affiliations}

${ }^{1}$ Department of Radiology, University of Calgary, Calgary, Alberta, Canada ${ }^{2}$ Alberta Children's Hospital Research Institute, University of Calgary, Calgary, Alberta, Canada

${ }^{3}$ Hotchkiss Brain Institute, University of Calgary, Calgary, Alberta, Canada ${ }^{4}$ Department of Pediatrics, University of Calgary, Calgary, Alberta, Canada

${ }^{5}$ Social Work, Mount Royal University, Calgary, Alberta, Canada

${ }^{6}$ Faculty of Education, University of Alberta, Edmonton, Alberta, Canada ${ }^{7}$ Department of Biomedical Engineering, University of Alberta, Edmonton, Alberta, Canada

${ }^{8}$ Werklund School of Education, University of Calgary, Calgary, Alberta, Canada

Contributors CAL, BG, CT, JP, CB, MB and CAM contributed to conceptualisation of this study. CAL wrote the first draft of this manuscript; all authors (CAL, BG, CT, JP, $\mathrm{CB}, \mathrm{MB}$ and $\mathrm{CAM}$ ) edited the manuscript and approved the final version.

Funding This work is supported by the Canadian Institutes of Health Research (PJT-162217).

Competing interests None declared. 
Patient and public involvement Patients and/or the public were involved in the design, or conduct, or reporting, or dissemination plans of this research. Refer to the Methods section for further details.

Patient consent for publication Not required.

Provenance and peer review Not commissioned; peer reviewed for ethical and funding approval prior to submission.

Open access This is an open access article distributed in accordance with the Creative Commons Attribution Non Commercial (CC BY-NC 4.0) license, which permits others to distribute, remix, adapt, build upon this work non-commercially, and license their derivative works on different terms, provided the original work is properly cited, appropriate credit is given, any changes made indicated, and the use is non-commercial. See: http://creativecommons.org/licenses/by-nc/4.0/.

ORCID iD

Catherine A Lebel http://orcid.org/0000-0002-0344-4032

\section{REFERENCES}

1 Cook JL, Green CR, Lilley CM, et al. Fetal alcohol spectrum disorder: a guideline for diagnosis across the lifespan. Can Med Assoc J 2016;188:191-7.

2 Flannigan K, Unsworth K, Harding K. The prevalence of fetal alcohol spectrum disorder, 2018.

3 Popova S, Lange S, Chudley A. World Health organization International study on the prevalence of fetal alcohol spectrum disorder (FASD) Canadian component; 2018.

4 Thanh NX, Jonsson E. Costs of fetal alcohol spectrum disorder in Alberta, Canada. Can J Clin Pharmacol 2009;16. [Epub ahead of print: 16 Jan 2009].

5 Stade B, Ungar WJ, Stevens B. Cost of fetal alcohol spectrum disorder in Canada. Can Fam Physician 2007;53:1303-4.

6 Kodituwakku PW. Defining the behavioral phenotype in children with fetal alcohol spectrum disorders: a review. Neurosci Biobehav Rev 2007;31:192-201.

7 May PA, Baete A, Russo J, et al. Prevalence and characteristics of fetal alcohol spectrum disorders. Pediatrics 2014;134:855-66.

8 Pei J, Denys K, Hughes J, et al. Mental health issues in fetal alcohol spectrum disorder. J Ment Health 2011;20:473-83.

9 Smetanin P, Stiff D, Briante C. The life and economic impact of major mental illnesses in Canada: 2011 to 2041; 2011.

10 Famy C, Streissguth AP, Unis AS. Mental illness in adults with fetal alcohol syndrome or fetal alcohol effects. Am J Psychiatry 1998;155:552-4.

11 Fagerlund A, Autti-Rämö I, Hoyme HE, et al. Risk factors for behavioural problems in foetal alcohol spectrum disorders. Acta Paediatr 2011;100:1481-8.

12 Denys K, Rasmussen C, Henneveld D. The effectiveness of a community-based intervention for parents with FASD. Community Ment Health J 2011;47:209-19.

13 Anderson T, Mela M, Stewart M. The implementation of the 2012 mental health strategy for Canada through the lens of FASD. Can J Commun Ment Health 2017;36:69-81.

14 Flannigan K, Coons-Harding KD, Anderson T, et al. A systematic review of interventions to improve mental health and substance use outcomes for individuals with prenatal alcohol exposure and fetal alcohol spectrum disorder. Alcohol Clin Exp Res 2020;44:2401-30.

15 Donald KA, Eastman E, Howells FM, et al. Neuroimaging effects of prenatal alcohol exposure on the developing human brain: a magnetic resonance imaging review. Acta Neuropsychiatr 2015;27:251-69.

16 Lebel C, Roussotte F, Sowell ER. Imaging the impact of prenatal alcohol exposure on the structure of the developing human brain. Neuropsychol Rev 2011;21:102-18.

17 Nardelli A, Lebel C, Rasmussen C, et al. Extensive deep gray matter volume reductions in children and adolescents with fetal alcohol spectrum disorders. Alcohol Clin Exp Res 2011;35:no-17.

18 Beaulieu C. The basis of anisotropic water diffusion in the nervous system - a technical review. NMR Biomed 2002;15:435-55.

19 Wozniak JR, Muetzel RL. What does diffusion tensor imaging reveal about the brain and cognition in fetal alcohol spectrum disorders? Neuropsychol Rev 2011;21:133-47.

20 Lebel C, Rasmussen C, Wyper K, et al. Brain diffusion abnormalities in children with fetal alcohol spectrum disorder. Alcohol Clin Exp Res 2008;32:1732-40.
21 Wozniak JR, Mueller BA, Chang P-N, et al. Diffusion tensor imaging in children with fetal alcohol spectrum disorders. Alcohol Clin Exp Res 2006;30:1799-806.

22 Andre QR, Geeraert BL, Lebel C. Brain structure and internalizing and externalizing behavior in typically developing children and adolescents. Brain Struct Funct 2020;225:1369-78.

23 Donald KA, Roos A, Fouche J-P, et al. A study of the effects of prenatal alcohol exposure on white matter microstructural integrity at birth. Acta Neuropsychiatr 2015;27:197-205.

$24 \mathrm{Kar}$ P, Reynolds JE, Grohs MN, et al. White matter alterations in young children with prenatal alcohol exposure. Dev Neurobiol 2021. doi:10.1002/dneu.22821. [Epub ahead of print: 08 Apr 2021].

25 van den Heuvel MP, Hulshoff Pol HE. Exploring the brain network: a review on resting-state fMRI functional connectivity. Eur Neuropsychopharmacol 2010;20:519-34.

26 Wozniak JR, Mueller BA, Bell CJ, et al. Global functional connectivity abnormalities in children with fetal alcohol spectrum disorders. Alcohol Clin Exp Res 2013;37:748-56.

27 Wozniak JR, Mueller BA, Mattson SN, et al. Functional connectivity abnormalities and associated cognitive deficits in fetal alcohol spectrum disorders (FASD). Brain Imaging Behav 2017;11:1432-45.

28 Long X, Kar P, Gibbard B, et al. The brain's functional connectome in young children with prenatal alcohol exposure. Neuroimage Clin 2019;24:102082.

29 Long X, Little G, Beaulieu C, et al. Sensorimotor network alterations in children and youth with prenatal alcohol exposure. Hum Brain Mapp. In Press 2018;39:2258-68.

30 Zhou D, Rasmussen C, Pei J, et al. Preserved cortical asymmetry despite thinner cortex in children and adolescents with prenatal alcohol exposure and associated conditions. Hum Brain Mapp 2018;39:72-88.

31 Paolozza A, Treit S, Beaulieu C, et al. Diffusion tensor imaging of white matter and correlates to eye movement control and psychometric testing in children with prenatal alcohol exposure. Hum Brain Mapp 2017;38:444-56.

32 Treit S, Zhou D, Lebel C, et al. Longitudinal MRI reveals impaired cortical thinning in children and adolescents prenatally exposed to alcohol. Hum Brain Mapp 2014;35:4892-903.

33 Lebel C, Mattson SN, Riley EP, et al. A longitudinal study of the long-term consequences of drinking during pregnancy: heavy in utero alcohol exposure disrupts the normal processes of brain development. J Neurosci 2012;32:15243-51.

34 Treit S, Lebel C, Baugh L, et al. Longitudinal MRI reveals altered trajectory of brain development during childhood and adolescence in fetal alcohol spectrum disorders. $J$ Neurosci 2013;33:10098-109.

35 Gautam P, Lebel C, Narr KL, et al. Volume changes and brainbehavior relationships in white matter and subcortical gray matter in children with prenatal alcohol exposure. Hum Brain Mapp 2015;36:2318-29.

36 Green CR, Lebel C, Rasmussen C, et al. Diffusion tensor imaging correlates of saccadic reaction time in children with fetal alcohol spectrum disorder. Alcohol Clin Exp Res 2013;37:1499-507.

37 Lebel C, Rasmussen C, Wyper K, et al. Brain microstructure is related to math ability in children with fetal alcohol spectrum disorder. Alcohol Clin Exp Res 2010;34:354-63.

38 Treit S, Chen Z, Zhou D, et al. Sexual dimorphism of volume reduction but not cognitive deficit in fetal alcohol spectrum disorders: a combined diffusion tensor imaging, cortical thickness and brain volume study. Neuroimage Clin 2017;15:284-97.

39 Andre QR, McMorris CA, Kar P, et al. Different brain profiles in children with prenatal alcohol exposure with or without early adverse exposures. Hum Brain Mapp 2020;41:4375-85.

40 Drevets WC, Price JL, Furey ML. Brain structural and functional abnormalities in mood disorders: implications for neurocircuitry models of depression. Brain Struct Funct 2008;213:93-118.

41 Price JL, Drevets WC. Neurocircuitry of mood disorders. Neuropsychopharmacology 2010;35:192-216.

42 Kerestes R, Davey CG, Stephanou K, et al. Functional brain imaging studies of youth depression: a systematic review. Neuroimage Clin 2014;4:209-31.

43 Cullen KR, Gee DG, Klimes-Dougan B, et al. A preliminary study of functional connectivity in comorbid adolescent depression. Neurosci Lett 2009;460:227-31.

44 Cullen KR, Klimes-Dougan B, Muetzel R, et al. Altered white matter microstructure in adolescents with major depression: a preliminary study. J Am Acad Child Adolesc Psychiatry 2010;49:173-83.

45 Hulvershorn LA, Cullen K, Anand A. Toward dysfunctional connectivity: a review of neuroimaging findings in pediatric major depressive disorder. Brain Imaging Behav 2011;5:307-28. 
46 Adluru N, Luo Z, Van Hulle CA, et al. Anxiety-Related experiencedependent white matter structural differences in adolescence: a monozygotic twin difference approach. Sci Rep 2017;7:8749.

47 Liao M, Yang F, Zhang Y, et al. White matter abnormalities in adolescents with generalized anxiety disorder: a diffusion tensor imaging study. BMC Psychiatry 2014;14:41.

48 Ducharme S, Albaugh MD, Hudziak JJ, et al. Anxious/depressed symptoms are linked to right ventromedial prefrontal cortical thickness maturation in healthy children and young adults. Cereb Cortex 2014;24:2941-50.

49 Boes AD, McCormick LM, Coryell WH, et al. Rostral anterior cingulate cortex volume correlates with depressed mood in normal healthy children. Biol Psychiatry 2008;63:391-7.

50 Akhtar H, Bukhari F, Nazir M, et al. Therapeutic efficacy of neurostimulation for depression: techniques, current modalities, and future challenges. Neurosci Bull 2016;32:115-26.

51 Delaloye S, Holtzheimer PE. Deep brain stimulation in the treatment of depression. Dialogues Clin Neurosci 2014;16:83-91.

52 Milev RV, Giacobbe P, Kennedy SH, et al. Canadian network for mood and anxiety treatments (CANMAT) 2016 clinical guidelines for the management of adults with major depressive disorder: section 4. neurostimulation treatments. Can J Psychiatry 2016;61:561-75

53 Steinhausen HC, Spohr HL. Long-Term outcome of children with fetal alcohol syndrome: psychopathology, behavior, and intelligence. Alcohol Clin Exp Res 1998;22:334-8.

54 Spohr H-L, Willms J, Steinhausen H-C. Prenatal alcohol exposure and long-term developmental consequences. The Lancet 1993;341:907-10.

55 McLachlan K, Paolozza A, Kully-Martens K, et al. Unpacking the heterogeneity of cognitive functioning in children and adolescents with fetal alcohol spectrum disorder: determining the role of moderators and strengths. Adv Neurodev Disord 2017;1:271-82.

56 Burghy CA, Stodola DE, Ruttle PL, et al. Developmental pathways to amygdala-prefrontal function and internalizing symptoms in adolescence. Nat Neurosci 2012;15:1736-41.

57 MacQueen GM, Yucel K, Taylor VH, et al. Posterior hippocampal volumes are associated with remission rates in patients with major depressive disorder. Biol Psychiatry 2008;64:880-3.

58 Chen C-H, Ridler K, Suckling J, et al. Brain imaging correlates of depressive symptom severity and predictors of symptom improvement after antidepressant treatment. Biol Psychiatry 2007;62:407-14.

59 Astley SJ. Profile of the first 1,400 patients receiving diagnostic evaluations for fetal alcohol spectrum disorder at the Washington State Fetal Alcohol Syndrome Diagnostic \& Prevention Network. Can J Clin Pharmacol 2010;17:e132-64.

60 Lebel CA, McMorris CA, Kar P, et al. Characterizing adverse prenatal and postnatal experiences in children. Birth Defects Res 2019;111:848-58.

61 Flannigan K, Kapasi A, Pei J, et al. Characterizing adverse childhood experiences among children and adolescents with prenatal alcohol exposure and fetal alcohol spectrum disorder. Child Abuse Negl 2021:112:104888.

62 Felitti VJ, Anda RF, Nordenberg D, et al. Relationship of childhood abuse and household dysfunction to many of the leading causes of death in adults. The adverse childhood experiences (ACE) study. Am J Prev Med 1998;14:245-58.

63 Chapman DP, Whitfield CL, Felitti VJ, et al. Adverse childhood experiences and the risk of depressive disorders in adulthood. $J$ Affect Disord 2004;82:217-25.

64 Tottenham N, Hare TA, Quinn BT, et al. Prolonged institutional rearing is associated with atypically large amygdala volume and difficulties in emotion regulation. Dev Sci 2010;13:46-61.

65 Gee DG, Gabard-Durnam LJ, Flannery J, et al. Early developmental emergence of human amygdala-prefrontal connectivity after maternal deprivation. Proc Natl Acad Sci U S A 2013;110:15638-43.

66 Mehta MA, Golembo NI, Nosarti C, et al. Amygdala, hippocampal and corpus callosum size following severe early institutional deprivation: the English and Romanian adoptees study pilot. $J$ Child Psychol Psychiatry 2009;50:943-51.

67 Hanson JL, Adluru N, Chung MK, et al. Early neglect is associated with alterations in white matter integrity and cognitive functioning. Child Dev 2013;84:1566-78.

68 Behen ME, Muzik O, Saporta ASD, et al. Abnormal fronto-striatal connectivity in children with histories of early deprivation: a diffusion tensor imaging study. Brain Imaging Behav 2009;3:292-7.

69 Eluvathingal TJ, Chugani HT, Behen ME. Abnormal brain connectivity in children after early severe socioemotiona deprivation: a diffusion tensor imaging study. Pediatrics 2006;117:2093-100.
70 Bick J, Zhu T, Stamoulis C, et al. Effect of early institutionalization and foster care on long-term white matter development. JAMA Pediatr 2015;169:211-9.

71 McLaughlin KA, Sheridan MA, Gold AL, et al. Maltreatment exposure, brain structure, and fear conditioning in children and adolescents. Neuropsychopharmacology 2016;41:1956-64.

72 Gold AL, Sheridan MA, Peverill M, et al. Childhood abuse and reduced cortical thickness in brain regions involved in emotional processing. J Child Psychol Psychiatr 2016;57:1154-64.

73 Lam VYY, Raineki C, Takeuchi LE, et al. Chronic stress alters behavior in the forced swim test and underlying neural activity in animals exposed to alcohol prenatally: sex- and time-dependent effects. Front Behav Neurosci 2018;12:42.

74 McLachlan K, Zhou D, Little G, et al. Current socioeconomic status correlates with brain volumes in healthy children and adolescents but not in children with prenatal alcohol exposure. Front Hum Neurosci 2020;14:223.

75 Uban KA, Kan E, Wozniak JR, et al. The relationship between socioeconomic status and brain volume in children and adolescents with prenatal alcohol exposure. Front Hum Neurosci 2020;14:85.

76 McLaughlin KA, Sheridan MA. Beyond cumulative risk: a dimensional approach to childhood adversity. Curr Dir Psychol Sci 2016;25:239-45.

77 Kingery JN, Roblek TL, Suveg C, et al. They're not just "little adults": developmental considerations for implementing cognitivebehavioral therapy with anxious youth. J Cogn Psychother 2006;20:263-73.

78 Fernandes BS, Williams LM, Steiner J, et al. The new field of 'precision psychiatry'. BMC Med 2017;15:80.

79 McLachlan K, Andrew G, Pei J. Assessing FASD in young children: exploring clinical complexities and diagnostic challenges. J Popul Ther Clin Pharmacol 2015;22:e108-24.

80 Kessler RC, Amminger GP, Aguilar-Gaxiola S. Age of onset of mental disorders: a review of recent literature. Curr Opin Psychiatry 2007;20:359-64.

81 Greene DJ, Koller JM, Hampton JM, et al. Behavioral interventions for reducing head motion during MRI scans in children. Neuroimage 2018;171:234-45.

82 Lebel C, Beaulieu C. Longitudinal development of human brain wiring continues from childhood into adulthood. J Neurosci 2011;31:10937-47.

83 Fischl B. FreeSurfer. Neuroimage 2012;62:774-81.

84 Reuter M, Schmansky NJ, Rosas HD, et al. Within-subject template estimation for unbiased longitudinal image analysis. Neuroimage 2012;61:1402-18.

85 Geeraert BL, Lebel RM, Mah AC, et al. A comparison of inhomogeneous magnetization transfer, myelin volume fraction, and diffusion tensor imaging measures in healthy children. Neuroimage 2018;182:343-350.

86 Mah A, Geeraert B, Lebel C. Detailing neuroanatomica development in late childhood and early adolescence using NODDI. PLoS One 2017;12:e0182340.

87 Cox RW. AFNI: software for analysis and visualization of functional magnetic resonance Neurolmages. Computers and Biomedical Research 1996;29:162-73.

88 Jenkinson M, Beckmann CF, Behrens TEJ, et al. Fsl. Neuroimage 2012;62:782-90.

89 Wilke M, Schmithorst VJ, Holland SK. Assessment of spatial normalization of whole-brain magnetic resonance images in children. Hum Brain Mapp 2002;17:48-60.

90 Reynolds C, Kamphaus R. Behavioral assessment system for children, second edition. San Antonio, TX: Pearson, 2004.

91 Kovacs M. Children's Depression Inventory 2. Pearson Clinical, 2010.

92 March JS. Multidimensional anxiety scale for children. 2nd edn. Pearson Clinical, 2012.

93 March JS, Parker JD, Sullivan K, et al. The multidimensional anxiety scale for children (MASC): factor structure, reliability, and validity. $J$ Am Acad Child Adolesc Psychiatry 1997;36:554-65.

94 Beck AT, Ward CH, Mendelson M. An inventory for measuring depression. Arch Gen Psychiatry 1961;4:561-71.

95 Cella D, Choi SW, Condon DM, et al. PROMIS ${ }^{\circledR}$ Adult Health Profiles: Efficient Short-Form Measures of Seven Health Domains. Value Health 2019;22:537-44.

96 Kaufman J, Birmaher B, Brent D, et al. Schedule for affective disorders and schizophrenia for school-age Children-Present and lifetime version (K-SADS-PL): initial reliability and validity data. J Am Acad Child Adolesc Psychiatry 1997;36:980-8.

97 American Psychological Association. Diagnostic and statistical manual of mental disorders. 5th edn. Arlington, VA: American Psychiatric Publishing, 2013. 
98 Tolin DF, Gilliam C, Wootton BM, et al. Psychometric properties of a structured diagnostic interview for DSM-5 anxiety, mood, and obsessive-compulsive and related disorders. Assessment 2018;25:3-13

99 Noel M, Wilson AC, Holley AL, et al. Posttraumatic stress disorder symptoms in youth with vs without chronic pain. Pain 2016;157:2277-84.

100 Palermo TM, Valenzuela D, Stork PP. A randomized trial of electronic versus paper pain diaries in children: impact on compliance, accuracy, and acceptability. Pain 2004;107:213-9.

101 Harrison PL, Oakland T. ABAS-3: adaptive behavior assessment system. 3rd edn. Torrance, CA: Psychological Corporation, 2015.

102 Dunn W. The Sensory Profile: User's Manual. San Antonio, TX: The Psychological Corporation, 1999.

103 Wechsler D. Wechsler abbreviated scale of intelligence (WASI). San Antonio, TX: The Psychological Corporation, 1999.

104 Bernstein JH, Waber DP. Developmental scoring system for the Rey-Osterrieth complex figure. Psychological Assessment Resources 1996.

105 Heaton RK, Chelune GJ, Talley JL. Wisconsin card sorting test manual: revised and expanded. Odessa, FL: Psychological Assessment Resources, 1993.

106 Delis DC. CVLT-C: California verbal learning test. San Antonio, TX: Psychological Corporation, 1994.
107 Korkman M, Kirk U, NEPSY KS II. Clinical and interpretative manual. San Antonio, TX: The Psychological Corporation, 2007.

108 Wechsler D. Wechsler individual achievement test. 3rd edn. London, 2009.

109 National Crittenton Foundation. The adverse childhood experiences (ACEs) survey: toolkit for providers 2015.

110 National Crittenton Foundation. Adverse childhood experiences (ACE) questionnaire and Crittenton 2013.

111 Bates D, Mächler M, Bolker B, et al. Fitting Linear Mixed-Effects Models Using Ime4. J Stat Softw 2015;67:48.

112 Kuznetsova A, Brockhoff PB, Christensen RHB. ImerTest Package: Tests in Linear Mixed Effects Models. J Stat Softw 2017;82:26.

113 Hayes AF. Introduction to mediation, moderation, and conditional process analysis. New York, USA: Guilford Press, 2013.

114 Bennett DS, Pendley JS, Bates JE. Daughter and mother report of individual symptoms on the children's depression inventory. Journal of Adolescent Health 1997;20:51-7.

115 Wei C, Hoff A, Villabø MA, et al. Assessing anxiety in youth with the multidimensional anxiety scale for children. $J$ Clin Child Adolesc Psychol 2014;43:566-78.

116 Fritz MS, Mackinnon DP. Required sample size to detect the mediated effect. Psychol Sci 2007;18:233-9. 